\title{
Progress on the health-related Sustainable Development Goals in Eastern Mediterranean Region countries: getting back on track in the time of COVID-19
}

\author{
Henry Victor Doctor, ${ }^{1}$ Ruth Mabry, ${ }^{2}$ Chodziwadziwa Whiteson Kabudula, ${ }^{3}$ Arash Rashidian, ${ }^{4}$ Rana Hajjeh, ${ }^{5}$ Syed Jaffar Hussain, ${ }^{6}$ \\ and Ahmed Al-Mandhari ${ }^{7}$
}

${ }^{1}$ Coordinator, Information Systems for Health, Department of Science, Information and Dissemination, World Health Organization Regional Office for the Eastern Mediterranean, Cairo, Egypt. ${ }^{2}$ Independent Public Health Researcher and formerly Technical Officer, SDGs/Gender, Equity and Human Rights, World Health Organization Regional Office for the Eastern Mediterranean, Cairo, Egypt. ${ }^{3}$ MRC/Wits Rural Public Health and Health Transitions Research Unit, School of Public Health, Faculty of Health Sciences, University of Witwatersrand, Johannesburg, South Africa. ${ }^{4}$ Director, Department of Science, Information and Dissemination, World Health Organization Regional Office for the Eastern Mediterranean, Cairo, Egypt. ${ }^{5}$ Director of Programme Management, World Health Organization Regional Office for the Eastern Mediterranean, Cairo, Egypt. ${ }^{6}$ World Health Organization Regional Office for the Eastern Mediterranean, Cairo, Egypt. ${ }^{7}$ Regional Director, World Health Organization Regional Office for the Eastern Mediterranean, Cairo, Egypt. (Correspondence to: Arash Rashidian: rashidiana@who.int).

Citation: Doctor HV; Mabry R; Kabudula CW; Rashidian A; Hajjeh R; Hussain SJ; et al. Progress on the health-related Sustainable Development Goals in Eastern Mediterranean Region countries: getting back on track in the time of COVID-19. East Mediterr Health J. 2021;27(6):530-534. https://doi. $\operatorname{org} / 10.26719 / 2021.27 \cdot 6.530$

Copyright (c) World Health Organization (WHO) 2021. Open Access. Some rights reserved. This work is available under the CC BY-NC-SA 3.0 IGO license (https://creativecommons.org/licenses/by-nc-sa/3.o/igo)

On 16 June 2021, the World Health Organization (WHO) launched its first report on the 'Progress on the healthrelated Sustainable Development Goals (SDGs) and targets in the Eastern Mediterranean Region' (1). This report presents for the first time a snapshot of the progress made in addressing the health-related SDG targets and indicators in the Region. It is an important mid-way report in recognizing the achievement, and most importantly, the challenges in reaching healthrelated objectives among the 17 SDGs adopted by the United Nations (UN) General Assembly in 2015 in the Eastern Mediterranean Region (2,3). WHO commitment to SDGs has been re-emphasized in its Thirteenth General Programme of Work and in the Regional Vision, 'Health for All by All' (4).

The report uses data reported by Member States and global estimates from WHO and other UN agencies from January 2010 to September $2020(5,6)$. In total, 50 health-related SDG indicators (across 9 out of 17 SDGs) are analyzed and presented. The report shows that availability of data for health-related SDG indicators varied considerably for the period, with huge gaps across indicators for cause-specific mortality, hepatitis prevalence, health financing and access to medicine indicators. Notably, the striking result is that the Region is not quite on track in meeting the health-related SDGs (7). Progress was made on only half of the 50 indicators reported between 2015 and 2019, before the COVID-19 pandemic (Table 1).

The regional profile has glimmers of hope. There has been a decline in the reported number of new cases of HIV/AIDS and TB; improvements in routine vaccination coverage; sustained high proportion of births attended by skilled health workers; fewer malnourished children; and an increasing access to improved drinking-water and sanitation. However, the Region still has a long way to go in reducing maternal, child and neonatal mortality. Expansion of vaccination coverage remains suboptimal.
Progress in reducing the overall rates of HIV and malaria cases has stalled. Mortality rates due to noncommunicable diseases (NCDs) and pollution indicate no signs of a reduction. In addition to these concerns, the lessons learnt from the COVID-19 pandemic demonstrate $(8,9)$ an uphill struggle for most countries in their quest for SDGs if the pace of investment in health and action remains at the current rate.

Timely high-quality data are critical in order to monitor progress on the SDGs at the regional, national and subnational levels. Insufficient data meant that progress for one in four indicators could not even be reported for the Region. Data availability is a major concern and demands significant improvement in health information systems (HIS) in countries of the Region $(10,11)$. The development of a Regional Strategy (20212025) to strengthen HIS aims to address these concerns. Jointly developed in collaboration with national HIS stakeholders, the strategy outlines a comprehensive plan in improve HIS and create a more robust system for monitoring progress in health and ensure sufficient evidence to inform policies. But investing in HIS alone will not ensure progress on the health-related SDGs - action is required on many fronts including implementation of interventions to address existing health challenges.

The way forward is challenging but by working together countries and partners in the Region can accelerate progress. Hence key decisions and actions are inevitable. Good governance processes with strong leadership, including high level political commitment, multi-sectoral partnership, and a wholeof-society approach, are needed to meet the Sustainable Development Agenda. Those responsible for the health sector (i.e. SDG3 targets) should work with other sectors to address the determinants of health like poverty (SDG1), education (SDG4), gender equality (SDG5), climate change (SDG13) and health-related risks like nutrition (SDG2) and water and sanitation (SDG6) $(12,13)$. Establishment 


\section{Table 1 Summary of progress on the health-related SDGs, 2015-2019}

\section{Health-related SDG indicators}

Mortality

3.1.1 Maternal mortality ratio (per 100 ooo live births)

3.1.2 Births attended by skilled health personnel (\%)

3.2.1 Under-5 mortality rate (per 1000 live births) ${ }^{\mathrm{a}}$

3.2.2 Neonatal mortality rate (per 1000 live births) ${ }^{\mathrm{a}}$

3.4.1 Probability of dying from NCDs (between ages 30-69) (\%)

3.4.2 Suicide mortality rate (per 100000 population) ${ }^{\mathrm{a}}$

3.6.1 Mortality rate from road traffic injuries (per 100000 population)

3.9.1 Mortality rate attributed to household and ambient air pollution (per 100000 population)

3.9.2 Mortality rate attributed to unsafe water, unsafe sanitation and lack of hygiene (per 100000 population)

3.9.3 Mortality rate attributed to unintentional poisoning (per 100 ooo population)

$\begin{array}{ll}175 & 164 \\ 98 & 99 \\ 52 & 46 \\ 27 & 25 \\ 20.8 & 22.0 \\ 3.9 & \ldots \\ 23.5 & 21.8 \\ 31.6 & 41.5 \\ 1.8 & 1.4 \\ 1.6 & 1.5\end{array}$

164

9

25

1.8

1.5
Progress made but too slow to meet target

Progress fast enough

Progress made but too slow to meet target

Progress made but too slow to meet target

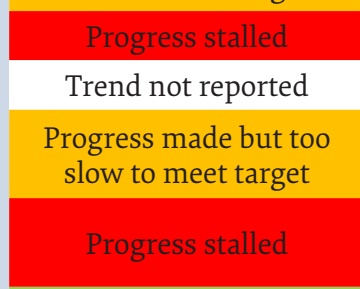

Progress

Progress

\section{Morbidity}

3.3.1 New HIV infections (per 1,000 uninfected people)

3.3.2 TB incidence (per 100000 population)

3.3.3 Malaria incidence (per 1000 population at risk)

3.3.4 Hepatitis B prevalence among children under 5 years

(per 100000 population)

3.3.5 Number of people requiring interventions for Leishmaniasis

$\begin{array}{cc}0.06 & 0.07 \\ 118 & 115 \\ 9 & 10 \\ 1.6 & \ldots \\ 10,616 & 15,367\end{array}$

\begin{tabular}{|c|}
\hline Progress stalled \\
\hline Progress \\
\hline Progress stalled \\
\hline Trend not reported \\
\hline Progress stalled
\end{tabular}

SDG3 means of implementation of targets

3.5.2 Harmful alcohol use (litres of pure alcohol per capita $\geq 15$ years)

3.7.1 Women of reproductive age (15-49 years) who had their need for family planning satisfied with modern methods (\%)

3.7.2: Adolescent birth rate (per 1000 women aged 15-19 years)

3.8.1 UHC service coverage index ${ }^{\mathrm{a}}$

3.8.2 Large household expenditure as a share of total health care expenditure $(>10 \%)$

3.8.2 Large household expenditure as a share of total health care expenditure $(>25 \%)$

3.a.1 Prevalence of tobacco use among persons 15 years and older (\%)

3.b.1 DPT3 Coverage (\%)

3.b.1 MCV2 Coverage (\%)

3.b.1 PCV3 Coverage (\%)

3.b.2 Official development assistance for medical research per capita (US\$)

3.b.3 Availability of essential medicines in public health facilities (\%)

3.c.1 Density of physicians (per 10000 population)

3.c.1 Density of pharmacists (per 10000 population)

3.c.1 Density of nurses (per 10000 population)

3.c.1 Density of dentists (per 10000 population)

3.d.1: International Health Regulations (IHR) capacity and health emergency preparedness
Progress

Progress

Progress

Progress made but too slow to meet target

Trend not reported

Trend not reported

Trend not reported

Progress

Progress

Progress

Progress

Few data points to determine trend

\section{Progress \\ Progress \\ Progress \\ Progress}

Trend not reported 




\section{Risk factors for health (direct effect on health)}

2.2.1 Stunting among children under 5 (\%)

2.2.1 Wasting among children under $5(\%)^{\mathrm{a}}$

2.2.2 Overweight among children under 5 (\%)

6.1.1 Access to improved drinking water (\%) ${ }^{\mathrm{a}}$

6.2.1 Access to improved sanitation facilities (\%)

11.6.2: Annual mean levels of fine particulate matter in cities $\left(\mathrm{mg} / \mathrm{m}_{3}\right)$

16.1.2 Conflict-related deaths (per 100000 population)

16.2.1: Proportion of children aged 1-17 years who experienced any physical punishment and/or psychological aggression by caregivers (\%)

.2
.0
89

89

75

3.3

\section{Progress \\ Progress fast enough

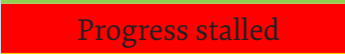 \\ Progress made but too slow to meet target \\ Progress made but too slow to meet target \\ Trend not reported Progress}

Trend not reported due to too few data points

\section{Determinants of health (indirect effect on health)}

1.1.1 Proportion of population living below the international poverty line 9\%)

4.1.1 Net primary school enrolment ratio (per 100 school-age children)

4.6.1 Literacy rate (15-24 years) (\%)

5.2.1 Proportion of ever-partners women and girls aged 15 years and older subjected to violence (\%)

5.6.1 Proportion of women aged 15-49 years who make their own informed decisions (\%)

8.5.2 Unemployment rate, males (\%)

8.5.2 Unemployment rate, females (\%)

8.5.2 Unemployment rate, both sexes (\%)

${ }^{a} \mathrm{SD}$ Gs with explicit targets for 2030 ;

... Limited data for most countries to assess regional progress or determine trend.

of coordinating or steering committees, with decision making power, that include key stakeholders are among effective ways that countries adopt for meeting SDGs. Successful examples of a whole-of society approach in controlling the COVID-19 pandemic are observed in a few countries of the Region (14) and maintaining and expanding such initiatives is the key in achieving WHO's vision for the Region (15).

It is for this reason that the WHO Regional Office for the Eastern Mediterranean embraced the Global Action Plan for Healthy Lives and Well-being (GAP), signed by 12 health and development partners (16). At least eight countries in the Region are using this approach to accelerate progress on the health-related SDGs. This plan also served as the background for the establishment of the Regional Health Alliance, launched in December

\section{0}

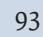

95

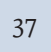

50.5

9

21

11

93
8

17
Trend not reported

Progress but data

available for selected countries

Progress but data

available for selected countries

Trend not reported

Trend not reported

\section{Progress \\ Progress \\ Progress}

\begin{tabular}{cl}
8 & Progress \\
17 & Progress \\
9 & Progress \\
\hline
\end{tabular}

2020 (17). The outcomes of this collaboration as a strategy to accelerate progress towards health-related SDGs at country and regional levels are visible.

As seen in the response during the pandemic, placing health at the top of the agenda means putting essential health services and universal health coverage at the forefront (18-20). The COVID-19 pandemic has uncovered many inequities and gaps in our health systems. In addition, the pandemic has all the hallmarks that suggest the progress towards SDGs might be hampered still further. Ensuring functioning health systems and effective governance mechanisms are at the forefront of efforts towards SDGs.

The delivery of health services must be complemented by a commitment to health at the highest levels of 
government. This means ensuring sustainable financial investment in basic health services and public health measures, including building resilient health systems to advance universal health coverage (UHC) (21). In addition, good governance is also reflected in laws and regulations. A commitment to the right to health also requires the means for its implementation. For example, NCDs are a major burden in the Region and the provision of health services will do little to address this when the key risk factors are behavioural, tobacco use, unhealthy diet and physical inactivity. Comprehensive approaches, including the implementation of regulations as outlined in the WHO 'Best Buys' (22), can markedly change the epidemiological profile of these diseases in the Region by 2030. As such, countries should "do something, do more, and do better" (23). Moreover, addressing gender equality and health inequities is essential if the Region is going to meet the health-related SDGs. Currently, the Region faces some of the greatest gender disparities and the health inequities between and within countries are vast. For the first time, the findings of the Regional Commission on the Social Determinants of Health outlined some of the major health inequities particular to the WHO Eastern Mediterranean Region.

At the global and regional levels, COVID-19 poses major challenges to health and well-being, thwarting progress to meet SDGs (24) and the WHO triple billion targets. While we are observing an increase in NCD burden and a greater number of immature deaths, the pandemic has demonstrated that communicable disease threats are real and might be expanding in coming years. Nevertheless, if necessary interventions are implemented and the necessary data are collected, processed and synthesized, progress towards health-related SDGs will not only be reliably measured, but would support countries' efforts to promote health and well-being (25). However, achieving this requires concerted efforts at the country, regional and global levels. The report, as noted above, provides a strong standing for developing a regional action plan that involves all key partners, and guide the efforts towards SDGs.

\section{References}

1. World Health Organization Regional Office for the Eastern Mediterranean (WHO/EMRO). Progress on the health-related Sustainable Development Goals and Targets in the Eastern Mediterranean Region, 2020. Cairo: WHO/EMRO; 2021. (http://www. emro.who.int/entity/statistics/statistics.html).

2. United Nations General Assembly. Transforming our world: the 2030 Agenda for Sustainable Development (Resolution A/ RES/70/1). New York: United Nations; 2015 (http://www.un.org/ga/search/view_doc.asp?symbol=A/RES/70/1\&Lang=E).

3. World Health Organization. Health in 2015: from MDGs, Millennium Development Goals to SDGs, Sustainable Development Goals. Geneva: World Health Organization; 2015 (https://www.who.int/docs/default-source/gho-documents/health-in-2015mdgs-to-sdgs/health-in-2015-from-mdgs-to-sdgs.pdf?sfvrsn=8ba61059_2).

4. World Health Organization Regional Office for the Eastern Mediterranean (WHO/EMRO). WHO's strategy for the Eastern Mediterranean Region, 2020-2023: Turning Vision 2023 into action. Cairo: WHO/EMRO; 2019; (https://applications.emro.who. int/docs/EMRPUB-RDO-014-2019-EN.pdf).

5. World Health Organization Regional Office for the Eastern Mediterranean (WHO/EMRO). Eastern Mediterranean Health Observatory Framework for SDG and Core Health Indicators. Cairo: WHO/EMRO; 2019 (https://rho.emro.who.int/emr-hf).

6. World Health Organization Regional Office for the Eastern Mediterranean (WHO/EMRO). Health and well-being profile of the Eastern Mediterranean Region: an overview of the health situation in the Region and its countries in 2019. Cairo: 2020. (https:// applications.emro.who.int/docs/9789290223399-eng.pdf?ua=1\&ua=1).

7. World Health Organization Regional Office for the Eastern Mediterranean (WHO/EMRO). Progress on the health-related Sustainable Development Goals and Targets in the Eastern Mediterranean Region, 2020. Cairo: WHO/EMRO; 2021. (http://www. emro.who.int/entity/statistics/statistics.html).

8. Mataria A, Brennan R, Rashidian A, Hutin Y, Hammerich A, El-Adawy M, Hajjeh R. 'Health for All by All' during a pandemic: 'Protect Everyone' and 'Keep the Promise' of Universal Health Coverage in the Eastern Mediterranean Region. East Mediterr Health J. 2020;26(12):1436-1439. https://doi.org/10.26719/2020.26.12.1436

9. Abubakar A, Al-Mandhari A, Brennan R, Chaudhri I, Elfakki E, Fahmy K, et al. Efforts to deploy COVID-19 vaccine in the WHO Eastern Mediterranean Region within the first 100 days of 2021. East Mediterr Health J. 2021;27(5):433-437. https://doi. org/10.26719/emhj.21.024. PMID: 34080669.

10. Rashidian A. Effective health information systems for delivering the Sustainable Development Goals and the universal health coverage agenda. East Mediterr Health J. 2019;25(12):849-851. https://doi.org/10.26719/2019.25.12.849

11. Doctor H, Rashidian A, Hajjeh R, Al-Mandhari A. Improving health and mortality data in Eastern Mediterranean Region countries: implementation of the International Classification of Diseases, 11th Revision (ICD-11). East Mediterr Health J. 2021;27(2):111112. https://doi.org/10.26719/2021.27.2.111. PMID: 33665793 
12. Al-Mandhari A, Marmot M, Ghaffar A, Hajjeh R, Allen J, Khan W, et al. COVID-19 pandemic: a unique opportunity to 'build back fairer' and reduce health inequities in the Eastern Mediterranean Region. East Mediterr Health J. 2021;27(3):217-219. https://doi. org/10.26719/2021.27.3.217. PMID: 33788208.

13. World Health Organization Regional Office for the Eastern Mediterranean (WHO/EMRO). Building back fairer, achieving health equity in the Eastern Mediterranean Region: report of the Commission on Social Determinants of Health in the Eastern Mediterranean Region. Cairo: WHO/EMRO; 2021. (http://www.emro.who.int/media/news/report-of-the-commission-on-social-determinants-of-health-in-the-eastern-mediterranean-region.html).

14. World Health Organization. Responding to the COVID-19 pandemic: WHO's action in countries, territories and areas, 2020. Geneva: World Health Organization; 2021 (https://apps.who.int/iris/handle/10665/339562).

15. World Health Organization Regional Office for the Eastern Mediterranean (WHO/EMRO). WHO's strategy for the Eastern Mediterranean Region, 2020-2023: Turning Vision 2023 into action. Cairo: WHO/EMRO; 2019; (https://applications.emro.who. int/docs/EMRPUB-RDO-014-2019-EN.pdf).

16. World Health Organization. (2019). Stronger collaboration, better health: global action plan for healthy lives and well-being for all: strengthening collaboration among multilateral organizations to accelerate country progress on the health-related Sustainable Development Goals. Geneva: World Health Organization; 2019 (https://apps.who.int/iris/handle/10665/327841).

17. World Health Organization Regional Office for the Eastern Mediterranean (WHO/EMRO). The Regional Health Alliance: A partnership towards achieving Health For All By All. Cairo: WHO/EMRO; 2020 (http://www.emro.who.int/media/news/the-regionalhealth-alliance-a-partnership-towards-achieving-health-for-all-by-all.html).

18. Khudadad U, Safi N, Aftab W, Ali A, Siddiqi S. The COVID-19 pandemic: an opportunity to strengthen health systems in Afghanistan. East Mediterr Health J. 2021;27(3):220-223. https://doi.org/10.26719/emhj.21.007. PMID: 33788209.

19. Eaton J, Rahman A, Gater R, Saxena S, Hammerich A, Saeed K. From adversity to resilience in the COVID-19 era: strengthening mental health systems in the Eastern Mediterranean Region. East Mediterr Health J. 2020;26(10):1148-1150. https://doi. org/10.26719/2020.26.10.1148. PMID: 33103740.

20. Konings F, Barakat A, Hutin Y, Hajjeh R. COVID-19 highlights the need for a strong health laboratories foundation for infectious disease surveillance and control in the Eastern Mediterranean Region. East Mediterr Health J. 2020;26(6):633-635. https://doi. org/10.26719/emhj.20.074. PMID: 32621494.

21. Mataria A, Brennan R, Rashidian A, Hutin Y, Hammerich A, El-Adawy M, et al. 'Health for All by All' during a pandemic: 'Protect Everyone' and 'Keep the Promise' of Universal Health Coverage in the Eastern Mediterranean Region. East Mediterr Health J. 2020;26(12):1436-1439. https://doi.org/10.26719/2020.26.12.1436

22. World Health Organization. Tackling NCDs: 'best buys' and other recommended interventions for the prevention and control of noncommunicable diseases. World Health Organization. Geneva: World Health Organization; 2017 (https://apps.who.int/iris/ handle/10665/259232).

23. World Health Organization Regional Office for the Eastern Mediterranean (WHO/EMRO). Building back fairer, achieving health equity in the Eastern Mediterranean Region: report of the Commission on Social Determinants of Health in the Eastern Mediterranean Region. Cairo: WHO/EMRO; 2021. (http://www.emro.who.int/media/news/report-of-the-commission-on-social-determinants-of-health-in-the-eastern-mediterranean-region.html).

24. United Nations. Sustainable Development Goals Report 2020. New York: United Nations; 2020. (https://www.un.org/en/desa/sustainable-development-goals-report-2020).

25. World Health Organization Regional Office for the Eastern Mediterranean (WHO/EMRO). Health and well-being profile of the Eastern Mediterranean Region: an overview of the health situation in the Region and its countries in 2019. Cairo: WHO/EMRO; 2020. (https://applications.emro.who.int/docs/9789290223399-eng.pdf?ua=1\&ua=1). 